\title{
Microphysical properties of carbonaceous aerosol particles generated by laser ablation of a graphite target
}

\author{
T. Ajtai ${ }^{1}$, N. Utry ${ }^{2}$, M. Pintér ${ }^{2}$, G. Kiss-Albert ${ }^{2}$, R. Puskás ${ }^{3}$, Cs. Tápai ${ }^{2}$, G. Kecskeméti ${ }^{2}$, T. Smausz ${ }^{1}$, B. Hopp ${ }^{2}$, \\ Z. Bozóki ${ }^{1,2}$, Z. Kónya ${ }^{3,4}$, and G. Szabó ${ }^{2}$ \\ ${ }^{1}$ MTA-SZTE Research Group on Photoacoustic Spectroscopy, Szeged, Dóm tér 9, 6720, Hungary \\ ${ }^{2}$ University of Szeged, Department of Optics and Quantum Electronics, Szeged, Dóm tér 9, 6720, Hungary \\ ${ }^{3}$ Department of Applied and Environmental Chemistry, University of Szeged, Szeged, Rerrich Béla tér 1, 6720, Hungary \\ ${ }^{4}$ MTA-SZTE Reaction Kinetics and Surface Chemistry Research Group, Szeged, Rerrich Béla tér 1, 6720, Hungary \\ Correspondence to: T. Ajtai (ajtai@titan.physx.u-szeged.hu)
}

Received: 12 June 2014 - Published in Atmos. Meas. Tech. Discuss.: 30 September 2014

Revised: 17 February 2015 - Accepted: 18 February 2015 - Published: 12 March 2015

\begin{abstract}
In this work various microphysical properties including mass concentration, size distribution and morphology of aerosol particles generated by laser ablation of a high purity graphite sample were investigated in detail. Supplementary chemical analysis of the generated particles including microstructure investigation by high-resolution transmission electron microscopy (HRTEM) and Raman spectroscopy were also made. These measurements proved that the proposed method can be used to model the real atmospheric carbonaceous particulate under various climate relevant conditions regarding its specific properties investigated here. However, to introduce the presented methodology as a novel BC surrogate, further improvement and investigation including simplification in experimental setup, comprehensive analysis of thermochemical refractiveness and optical responses of the generated particles as well as comparative study with the presently available concurrent surrogates are required. The related results of these issues are planned to be demonstrated in other studies.
\end{abstract}

\section{Introduction}

Combustion-generated carbon particles (soot) have been in the focus of scientific interest, primarily because of their influence on climate as well as their adverse effects on human health (IPCC, 2007; Pope III and Dockery, 1999). Moreover, according to the latest scientific assessment, atmospheric soot, which is the by-product of incomplete combustion of both fossil and biomass fuel as well as biomass burning, is the second most important anthropogenic emission. Only $\mathrm{CO}_{2}$ has larger climatic impact (Bond et al., 2013). Atmospheric soot is a mixture of most refractory particles having strong but featureless optical absorption properties (the optical absorption shows inverse relation with wavelength) called elemental carbon (EC) or black carbon (BC) and organic carbon $(\mathrm{OC})$ that can have a wide range of thermal and optical absorption characteristics. Nevertheless, since atmospheric soot originates mainly from anthropogenic sources, its real-time and selective identification is also of crucial importance in terms of legal regulations (Kirchstetter et al., 2004; Hand et al., 2005). The identification and characterization of atmospheric soot is generally based on the measurement of its specific properties, i.e., absorption and scattering or size and morphology as well as its composition and refractivity. Although, many instruments have been developed and optimized to measure these quantities, one of the major obstacles to reduce uncertainties associated with the measured data is the lack of a soot standard reference material which is able to model the specific properties of the atmospheric soot that is actually measured (Baumgardner et al., 2012; Gysel et al., 2011). However, the parameters generally used to characterize atmospheric soot are very complex, have great variety, and depend not only on the initial burning conditions or the type of fuel but also on many environmental factors. Therefore, it is highly advantageous if the applied generation method can provide not only a model soot with a specific and complex set of parameters but can also modify all 

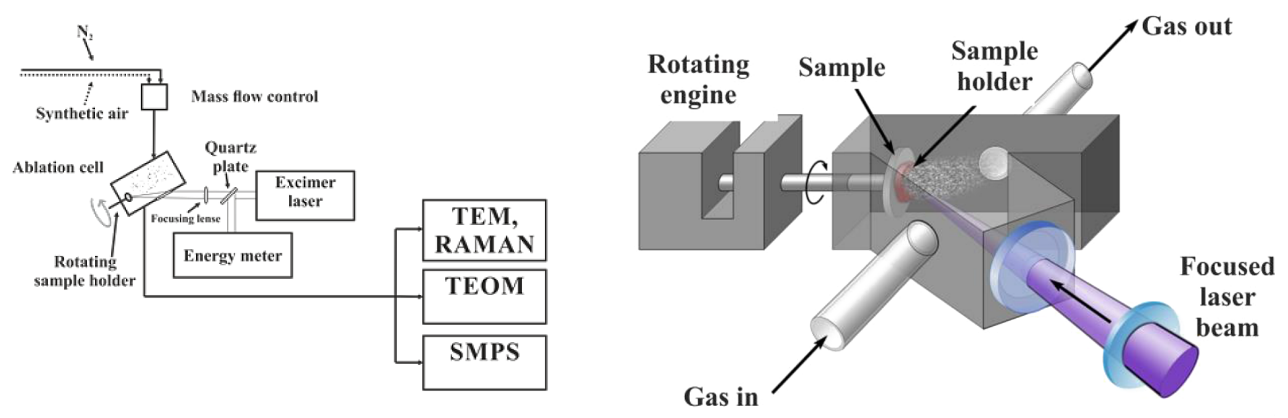

Figure 1. The schematic scheme of the experimental setup (left) and the modified PLD chamber (right).

relevant properties independently from each other preferably in the entire climate and health relevant domains. The standard techniques based on specially designed gas burners and graphite electrode spark dischargers only partially fulfil the above mentioned requirements (Schnaiter et al., 2006, 2003; Kirchstetter and Novakov, 2007), so introducing alternative methods for soot production is a relevant and actual scientific goal.

In this work, we propose a novel methodology for carbonaceous particle generation based on laser ablation of a graphite target. We present the characteristic microphysical features of particles generated by our proposed method such as mass concentration, size distribution and morphology as a function of generation parameters. These include, most importantly, the fluence of the ablation laser as well as the flow rate and the composition of the carrier gas. Furthermore, the microstructure and the Raman spectrum of the generated carbonaceous particles were investigated under various conditions.

\section{Experimental}

The generation and characterization of the carbonaceous aerosol particles were carried out in the following experimental arrangement (Fig. 1). Krypton fluoride (KrF) excimer laser (LLG TWINAMP) beam was focused by a fused silica lens onto the surface of the target material. The operational wavelength and the pulse duration (full width at half maximum) were $248 \mathrm{~nm}$ and $18 \mathrm{~ns}$, respectively. The applied laser was operated at a $1 \mathrm{~Hz}$ repetition rate. The laser energy on the surface of the ablated sample was determined as follows. A quartz plate was installed into the laser beam, which served as an energy coupler reflecting $4 \%$ of the laser energy onto the surface of an energy meter (Laser Probe Inc., Rm3700). This value, when divided by the irradiated sample area (which was measured to be $2.5 \mathrm{~mm}^{2}$ ) gives the laser fluence on the sample. The fluence was varied from $0.5-2.9 \mathrm{~J} \mathrm{~cm}^{-2}$ during the reported measurements. The target material for aerosol generation was a high purity graphite disc (Goodfellow, purity $>99.95 \%$ ) with a diameter and thickness of 3 and $5 \mathrm{~cm}$, respectively. The sample was placed and irradiated in an ablation chamber (Fig. 1), which was a modified version of a PLD (pulsed laser deposition) chamber described in detail earlier (Ajtai et al., 2010; Hopp et al., 2012). The cylindrically shaped ablation chamber was made of stainless steel with an inner diameter and length of 3 and $10 \mathrm{~cm}$, respectively. The focused laser beam was directed into the chamber through a fused silica window at an angle of $45^{\circ}$ with respect to the surface of the irradiated sample. In order to minimize the loss of the generated particles, the purging gas inlet and the outlet were milled onto the opposite sides of the ablation chamber ensuring a straight gas flow path through the chamber. This was the most important modification of the chamber, because in a typical PLD experiment the generated particles do not leave the chamber; therefore, the gas flow direction is irrelevant. To improve the stability of the yield of the ejected particles, the target was placed onto a rotating sample holder and the angular speed of rotation was matched to the repetition rate of the laser and the dimension of the irradiated spot in order to ensure uniform sample etching, i.e., quasi-homogeneous ablated target surface structure and consequently uniform material ejection over a long period of time. This way stable particle production could be realized for several hours. High purity nitrogen or synthetic air having 5.0 certified purity, as well as their mixtures was used as purging gas. The flow rate of purging gas was set and controlled by mass flow controllers (MFCs, Tylan 2900FC). The generated carbonaceous particles were carried by the purging gas into a dilution chamber from which the measuring instruments sucked the aerosol-laden sample streams. All the reported experiments were performed at room temperature and atmospheric pressure, with the latter ensured by an exhaust pipe attached to the dilution chamber (Fig. 1).

The number concentration and size distribution of the generated particles were measured in the size range of 10 to $1100 \mathrm{~nm}$ with a scanning mobility particle sizer (SMPS, GRIMM system Aerosol Technik, Germany, type SMPS) in two subsequent steps. First, the sampled aerosol stream was lead into a classifier "Vienna-type" long differential mobility analyzer (LDMA, Model \#5.500). The LDMA separates particles based on their mobility by balancing their drag 


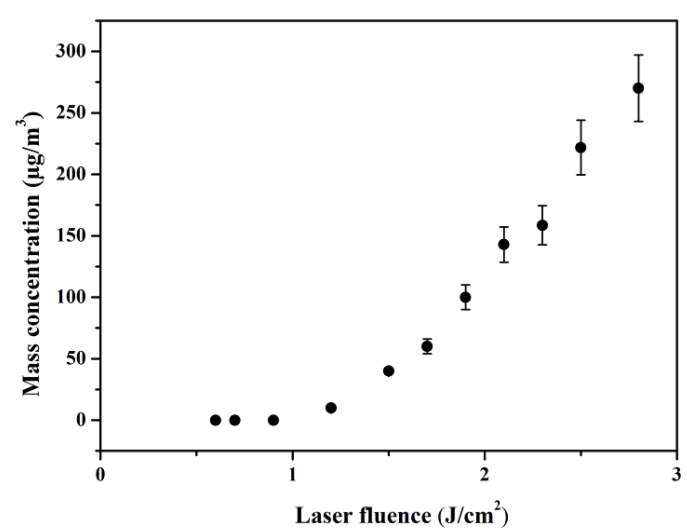

Figure 2. Mass concentration of ablation-generated carbonaceous aerosol particles as a function of the fluence of the $\mathrm{KrF}$ excimer laser. The error bar represents the standard deviation of the measured data including concentration and instrument instability.

and electrical force on the equally charged aerosol stream. Then the sized particles are sent to the condensation particle counter (CPC Model \#5.400) in which the size segregated particles are counted. In order to minimize the occurrence of the so-called shielding artifact, in which case two or more particles arrive in the detection chamber simultaneously, coincide correction of the measured data was performed. The sheath and aerosol flow rate were set to 3.0 and $0.3 \mathrm{~L} \mathrm{~min}^{-1}$, respectively.

Besides the online measurements, the morphology, the microstructures, and molecule structures of the generated particles were also investigated by a transmission electron microscope (FEI Tecnai G2 20 X-Twin) and by a Raman spectrometer (Thermo Scientific DXR Raman Microscope). The TEM (transmission electron microscopy) was operated at $200 \mathrm{kV}$ accelerating voltage. The TEM grid used for the investigation of the morphology was carbon film coated 200 mesh copper grid (CF200-Cu, Electron Microscopy Sciences, USA), while for the characterization of the microstructure of the primary particles lacey carbon grids (LC200-Cu, Electron Microscopy Sciences, USA) were used. Before imaging, the grid was placed in a polystyrene Petri dish and equilibrated in a desiccation chamber at $\sim 25^{\circ} \mathrm{C}$ and $\sim 20 \% \mathrm{RH}$. To measure the degree of crystallinity of graphene layers inside the primary particles, high resolution electron microscopy (HRTEM) mode was used with a point to point resolution of $0.26 \mathrm{~nm}$. In order to avoid the fractal displacement during the exposition on the grid in the HRTEM mode, the sample was preheated before imaging.

The mass concentration of the generated aerosol stream was measured by a tapered element oscillating microbalance (TEOM, Rupprecht and Patashnick, Model 1400a). TEOM incorporates an inertial balance that directly measures the mass of aerosol accumulated on an exchangeable filter cartridge by monitoring the corresponding frequency changes of a tapered element (Allen et al., 1997).

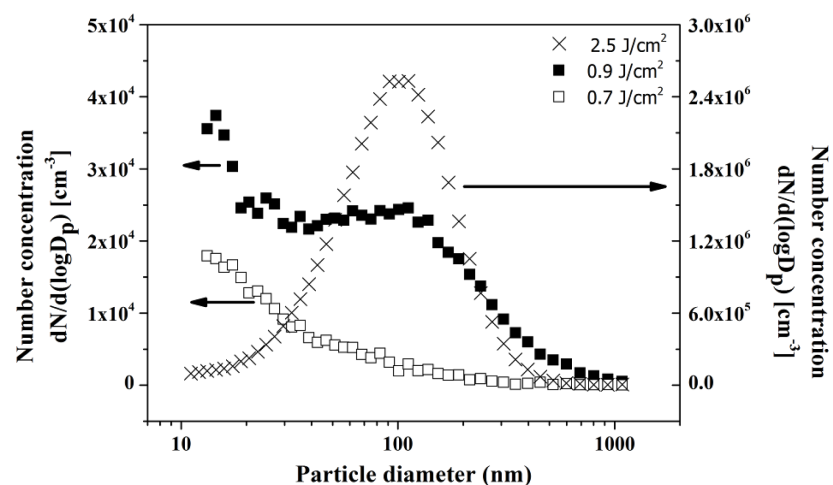

Figure 3. Number size distribution of the generated carbonaceous particles at three different laser fluences. Note: the right $y$ axis applies for the $2.5 \mathrm{~J} \mathrm{~cm}^{-2}$ fluence.

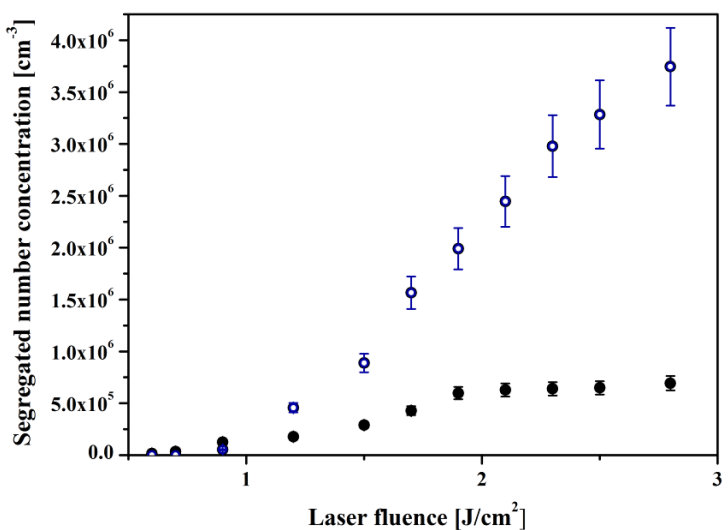

Figure 4. Segregated number concentrations in the two characteristic modes as a function of the laser fluence. Closed circles: primary particles, open circles: fractal aggregates. The error bar represents the standard deviation of the measured data including concentration and instrument instability.

\section{Results}

All the presented results correspond to measurements made when using nitrogen as a carrier gas with a volumetric flow rate of $500 \mathrm{~cm}^{3} \mathrm{~min}^{-1}$, unless otherwise stated. Aerosol mass concentration measured by the TEOM instrument as a function of the laser fluence can be seen in Fig. 2. The number size distribution of the generated carbonaceous particles measured at three different fluences is shown in Fig. 3. There are two identified characteristic modes in the number size distribution with a count median diameter (CMD) in the range of 15 and $100 \mathrm{~nm}$, which are called as primary particles and fractal aggregates in the following, respectively (see below). The segregated number concentrations in these two modes are shown as a function of laser fluence in Fig. 4. The CMD and the full width at half maximum (FWHM) of the fractal aggregate mode at different laser fluences are given in Table 1. The number size distribution of the laser-generated 
Table 1. Various parameters of the fractal aggregate mode as a function of the laser fluence in case of nitrogen carrier gas with a volumetric flow rate of $500 \mathrm{~cm}^{3} \mathrm{~min}^{-1}$.

\begin{tabular}{lrrrrrrrr}
\hline Fluence $\left[\mathrm{J} \mathrm{cm}^{-2}\right]$ & 1.25 & 1.5 & 1.7 & 1.9 & 2.1 & 2.3 & 2.5 & 2.8 \\
\hline CMD [nm] & 175.4 & 152.9 & 147.2 & 147.4 & 137.9 & 157.6 & 158 & 162.8 \\
FWHM [nm] & 233.8 & 196.9 & 158.3 & 157.4 & 137.1 & 163.8 & 164.7 & 169.3 \\
Modal number concentration $\left[10^{6} \mathrm{~cm}^{-3}\right]$ & 0.8 & 1 & 1.8 & 2.3 & 2.8 & 3.3 & 3.6 & 4.3 \\
\hline
\end{tabular}

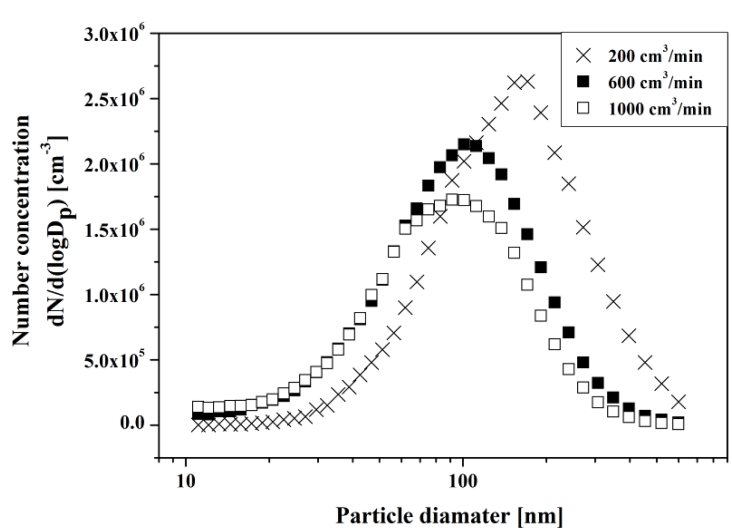

Figure 5. Number size distribution of the generated carbonaceous particles at three different volumetric flow rates of nitrogen purging gas at $2 \mathrm{~J} \mathrm{~cm}^{-2}$ fluence.

carbonaceous particles measured at three different volumetric flow rates of the nitrogen carrier gas using $2 \mathrm{~J} \mathrm{~cm}^{-2}$ fluence can be seen in Fig. 5. Figure 6 shows the measured number size distribution in case of different purging gases at $2 \mathrm{~J} \mathrm{~cm}^{-2}$ laser fluence and $500 \mathrm{~cm}^{3} \mathrm{~min}^{-1}$ volumetric flow rate. The TEM and HRTEM pictures taken of various generated particles are shown in Fig. 7. Finally, the Raman spectra of the laser-generated aerosol plume are depicted in Fig. 8.

\section{Discussion}

According to a simplified model, the particle formation process can be divided into three subsequent phases (Gelencsér, 2004):

In the nucleation phase, etching of the sample induces an ablation plume that contains different vapors and fragments originating from the destroyed target material. Then these components connect with different types of bonds, and the resulting nanoparticles serve as nuclei in the subsequent phases of particle generation.

In the coagulation phase, primary particles collide, and due to the favorable energy conditions they form a new, spherically shaped particle with a volume roughly equal to the sum of the volumes of the individual particles. However, the surface of the new particle is much smaller than the sum of the surfaces of the colliding ones.

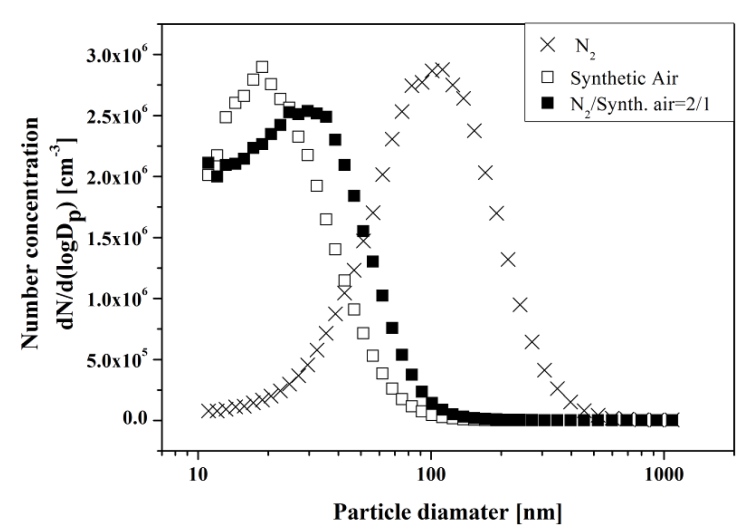

Figure 6. Number size distribution of the laser ablation-generated carbonaceous particles by applying different carrier gases with a volumetric flow rate of $500 \mathrm{~cm}^{3} \mathrm{~min}^{-1}$ at $2 \mathrm{~J} \mathrm{~cm}^{-2}$ fluence.

In the aggregation phase, colliding particles become weakly bonded to one another creating fractal aggregates with a complex morphology.

Nucleation can be classified as a gas to aerosol transition chemical process, while particle evolutions via coagulation or aggregation are physical processes. Coagulation and aggregation are competing processes, the ratio of coalescence and collision time determines their relative dominance (Hawa and Zachariah, 2006):

$\tau_{\text {coalescence }}>\tau_{\text {collision }} \rightarrow$ coagulation $\rightarrow$ spherical particles

$\tau_{\text {coalescence }}<\tau_{\text {collision }} \rightarrow$ aggregation $\rightarrow$ fractal aggregates

As far as our measurement results are concerned (Fig. 2), at fluences below $\sim 0.9 \mathrm{~J} \mathrm{~cm}^{-2}$ the mass concentration of the generated aerosol particles was found to be almost completely independent of the applied fluence, while above this limit the mass concentration increased roughly linearly with the fluence. This can be explained by the fact that at low fluences, the excitation causes fragmentations on the irradiated surface, which is a surface phenomenon and thus largely independent from the variation in fluence, while at higher fluences the yield of aerosol generation is proportional to the whole ablation volume determined by the penetration depth of the laser pulse. The latter is a volume effect; therefore aerosol yield in this regime is scaled by the laser fluence.

Depending on the applied laser fluence three characteristic domains can be identified in the measurement results: 
(a)
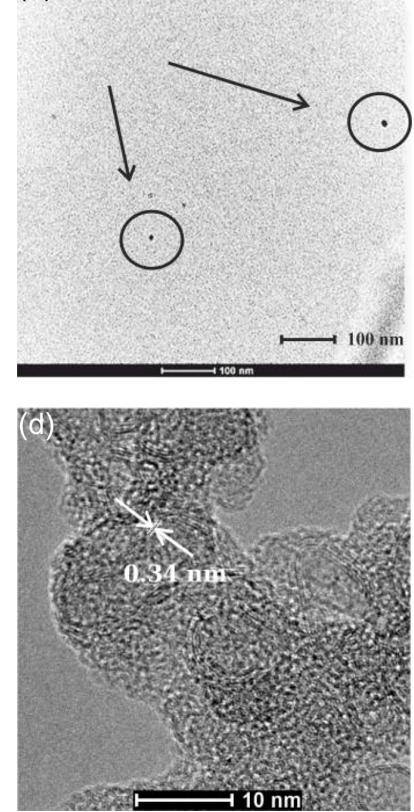

(b)
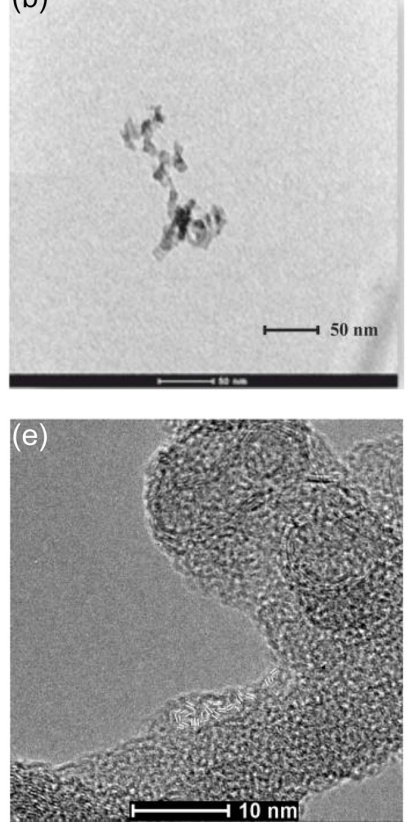
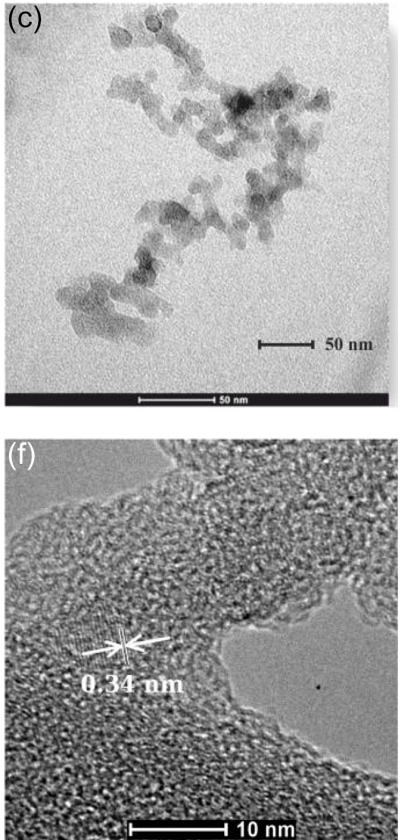

Figure 7. TEM and HRTEM images of various laser-generated carbonaceous aerosol particles. (a) Primary particles obeyed at $0.7 \mathrm{~J} \mathrm{~cm}^{-2}$ laser fluence at nitrogen purging gas, (b) and (c) more complicated fractal aggregates gathered at 0.9 and $2.5 \mathrm{~J} \mathrm{~cm}{ }^{-2}$ laser fluences in nitrogen purging gas respectively. In (d)-(f) typical microstructure of the generated particles are shown (see text in details).

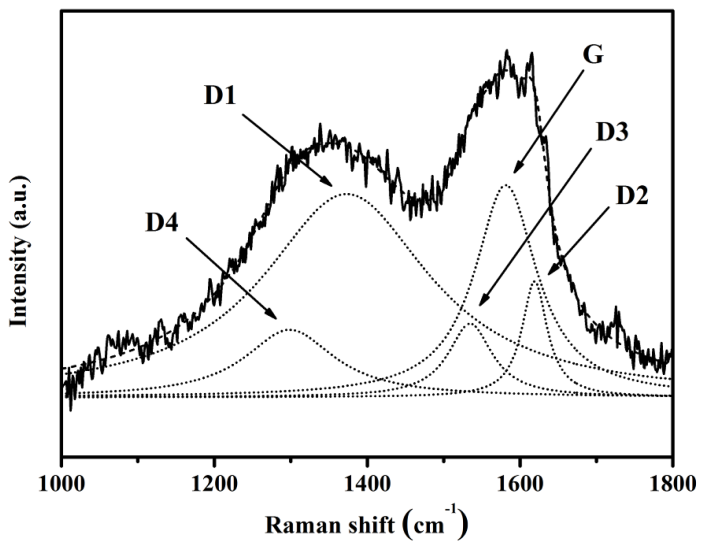

Figure 8. First-order Raman spectra and its mode structure: $G$ and D (D1-D4) modes represents the graphite and the disordered multi modes (see text in details). The black line represents the measured data, while the scattered line represents the fitted curves.

At low fluences the generated carbon aerosol plume dominantly contains a high number of small primary particles (see the curve corresponding to a fluence of $0.7 \mathrm{~J} \mathrm{~cm}^{-2}$ in Fig. 3) supposedly with a spherical shape (such as those shown in the TEM picture in Fig. 7a) and various sizes, while the number of aggregates is low, and they are typically built from a small number of monomers. In this region, either the number of primary particles is insufficient for efficient fractal aggregate generation, or the primary particles are too small for the aggregation process to take place. In either case, the results indicate that in this domain the coalescence time is much shorter than the collision time.

At intermediate fluences there are both primary particles and an increasing number of fractal aggregates in the plume (see the curve corresponding to a fluence of $0.9 \mathrm{~J} \mathrm{~cm}^{-2}$ in Fig. 3). With increasing fluence fractal aggregates with complex morphology (such as those shown in the TEM pictures in Fig. 7b and c) become dominant in the generated aerosol plume (Fig. 4). As it can be seen in Fig. 4, there is still also a relatively large number of primary particles in the generated plume. The coalescence time and the collision time are assumed to be roughly equal in this domain.

Finally, above $\sim 1.8 \mathrm{~J} \mathrm{~cm}^{-2}$ fractal aggregates become dominant (see the curve corresponding to the fluence of $2.5 \mathrm{~J} \mathrm{~cm}^{-2}$ in Fig. 3), and the yield of primary particles does not increase any further with fluence (Fig. 4). The most probable reason for such behavior is that at such high fluences all the primary particles in access of a certain limit are consumed by cluster formation. So the primary particles are sources of fractal aggregates, meanwhile the fractal aggregates are sinks of the primary particles. In this region the coalescence time has to be much longer than the collision time.

However, in the last two domains, the fluence of above $\sim 1 \mathrm{~J} \mathrm{~cm}^{-2}$ the generated fractal aggregates can be well characterized with a monodisperse log-normal size distribution with slightly fluence dependent CMD and FWHM values (Table 1). 
The reproducibility of the generated carbonaceous aerosol plume was determined from 60 spectra gathered from 2 hours continuous measurement period which was repeated 3 times on 3 different days at $2 \mathrm{~J} \mathrm{~cm}^{-2}$ laser fluence. The uncertainty of the CMD, FWHM and the total particle number concentration were found to be below $10 \%$ in all cases which is very typical in real-time soot generators (Spanner et al., 1994; Horvath and Gangl, 2003). Therefore, the non-monotonic changes in CMD observed by varying the fluence (Table 1) are within instrument uncertainty, while changes in the width of the yield distribution (FWHM) are outside the instrument uncertainty and may indicate some dependence on laser fluence. However, in the presented methodology, the main critical sources of errors are the optical alignment and the long term instability of the applied laser source. These and the uncertainty of gas flow rates of the purging gas mixtures $( \pm 5 \%)$ limit the reproducibility presently.

Finally, the morphology, the microstructure and the Raman spectra of the generated aerosol plume were investigated. In Fig. 7, three different, representative soot structures can be seen. These experimentally demonstrated that the morphology of the laser-generated soot aerosol well models the real carbonaceous atmospheric particulate originating from, i.e., diesel exhaust or a kerosene flame (Park et al., 2004; Fruhstorfer and Niessner, 1994; Randall and Vander, 2010). Figure 7 a represents primary particles with the average diameter of $7 \pm 0.8 \mathrm{~nm}$ which was collected at $0.7 \mathrm{~J} \mathrm{~cm}^{-2}$ fluence in nitrogen purging gas. Figure $7 \mathrm{~b}$ and c demonstrate more complex soot structures corresponding to 0.9 and $2.5 \mathrm{~J} \mathrm{~cm}^{-2}$ excitations, respectively. The mean particle diameter, calculated from about 200 primary particles, was found to be in between 8.5 and $13.7 \mathrm{~nm}$ with the average diameter of $9.9 \mathrm{~nm}$ with standard deviation of 2.3 in case of fractals aggregates (Fig. 7b and c). Fractal dimension of the generated carbonaceous aggregates was determined by using a simple relation between the number and mean diameter of primary particles as well as their radius of gyration with the aid of an image analysis software (Digital Micrograph 3, Gatan Inc.; Park et al., 2004). The fractal dimensions calculated from well separated aggregates on the grid associated with 0.9 and $2.5 \mathrm{~J} \mathrm{~cm}^{-2}$ fluences ranged from 1.65 to 2.1 with the mean value of $1.88 \pm 1.4$. Therefore, the morphology and the characteristic dimensions of the fractals experimentally demonstrated that the laser-generated carbonaceous aerosol particulate shows high similarity with real soot or soot containing ambient aerosol such as diesel or biodiesel soot (Tumolva et al., 2010; Song et al., 2004).

The structural properties of the primary particles obtained in the high resolution TEM mode at $2 \mathrm{~J} \mathrm{~cm}^{-2}$ fluence are shown in Fig. 7d-f. Besides some amorphous and disordered arrangements, the laser-generated soot typically forms in an onion (graphitic) structure where graphene layers are oriented parallel to the external outer surface (Fig. 7d), in a locally and concentrically structured graphene layers but with random orientation respect to each other (Fig. 7e), and graphene layers structured parallel to each other but without concentric orientation (Fig. 7f). The typical distance between the layers is about $0.34 \mathrm{~nm}$ (Fig. 7d). These types of microstructures are also in good agreement with a more realistic ambience or other artificially generated soot originating from i.e., diesel exhaust or spark discharged of a carbon rood (Sadecky et al., 2005; Sze et al., 2001; Jawhari et al., 1995; Mertes et al., 2004).

The Raman spectra of the laser-generated soot aerosol exhibit two broad and strongly overlapping peaks with the maximum intensity at around $1350 \mathrm{~cm}^{-1}$ and at around $1585 \mathrm{~cm}^{-1}$ (first-order) and one individual peak with relatively lower intensity laying between 2700 and $3500 \mathrm{~cm}^{-1}$ (second order) (Fig. 8). The latter one has not showed in Fig. 8. The feature around $1585 \mathrm{~cm}^{-1}$ designated to $\mathrm{G}$ (graphite) peak indicates the fundamental mode of a graphite crystal, while the peak around $1350 \mathrm{~cm}^{-1}$ denotes the D (disordered) lines mostly associated with amorphous or randomly oriented (turbostratic) graphene layer structures. The detailed analyses of the first-order spectra where the originally measured Raman data is further structured by a multipeak fitting algorithm including all first-order Raman bands of soot or soot containing materials (G and D1-D4) are also shown in Fig. 8 (Sadecky et al., 2005). The obeyed Raman spectra are in accordance with the results of the HRTEM images and further confirmed that the laser-generated aerosol plume well modeled the realistic soot or soot-containing ambient particulates (Tumolva et al., 2010; Song et al., 2004).

As it can be seen from the presented results the here proposed laser ablation method offers various advantages as a tool for carbonaceous particle generation.

- The mobility diameter of the generated particles ranges from 10 to $1100 \mathrm{~nm}$.

- The number concentration of the generated particles can be as high as $10^{7}$ particle $\mathrm{cm}^{-3}$ (in case of $2 \mathrm{~J} \mathrm{~cm}^{-2}$ fluence and nitrogen purging gas with a volumetric flow rate of $200 \mathrm{sccm})$.

- Depending on the experimental conditions, either small or large particles can be generated with high efficiency. For example, 20 or $600 \mathrm{~nm}$ particles can be generated with an efficiency of about $10^{5}$ particles $\mathrm{cm}^{-3}$ by using $2 \mathrm{~J} \mathrm{~cm}^{-2}$ fluence, synthetic air as purging gas with $500 \mathrm{sccm}$ volumetric flow rate and $2 \mathrm{~J} \mathrm{~cm}^{-2}$ fluence, nitrogen as purging gas with $200 \mathrm{sccm}$ volumetric flow rate, respectively.

- Particles with various complexity and microstructure can be generated (Fig. 7).

- As it can be seen in Fig. 4, the ratio of the number concentrations of aerosol particles in the fractal aggregate mode to the primary particle mode can be varied from 0 to about 5 quasi-linearly by increasing the laser fluence. 
- By changing either the laser fluence or the volumetric flow rate of the purging gas, it is possible to change the morphology of the generated aerosol in a controlled manner. As it can be seen in Fig. 5, both the segregated number concentration and the CMD value can be increased by reducing the gas flow rate. The number concentration increases, because at a lower volumetric flow rate a given volume of the carrier gas resides in the ablation chamber longer, while the emission rate of the ablated particles remains constant. Furthermore, a reduced the flow rate increases the probability of particle collision, which results in an increase in the size of the aggregates; i.e., this is why the CMD value increases.

- As far as the use of different purging gases is concerned, the proposed carbonaceous aerosol generation method offers great flexibility, too. We have demonstrated that by using different mixtures of $\mathrm{N}_{2}$ and synthetic air as purging gas, the particle generation process can be altered drastically and in a well-controlled manner (Fig. 6). Moreover, compared to nitrogen buffer gas the generation of fractal aggregates are largely suppressed in gas mixtures that also contain synthetic air, presumably due to the concomitant oxidation. This effect can strongly modify the interpretation of the chemical analysis of the generated particles. However, this study only serves to demonstrate the variability of the presented methodology regardless of the detailed investigation of the gas to particle interaction during the particle formation, i.e., contamination of the generated particles by the composition of purging gases; therefore, further studies are needed to investigate the possibilities and advantages of using other types of purging gases. Further studies are needed to investigate the possibilities and advantages of using other types of purging gases, i.e., using argon to avoid the nitrogen contamination of the generated primary particles (Voevodin et al., 2002; Ritikos et al., 2011; Yang et al, 2007).

- Special advantages of the method are that the target material can also be changed from any real solid phase target sample so, the real combustion processes such as biomass or coal burning can be modeled accurately in this setup as well (Ajtai et al., 2010).

- Finally, besides its flexibility, one of the major advantages of the proposed method is that all the parameters of the generated aerosol plume can be tuned independently from each other.

As a result of the advantages listed above, the laser ablation method has a high flexibility and consequently, it offers a novel possibility of generating carbonaceous particulates with atmospherically relevant parameters as far as mass concentration, aerosol modes, size distribution, morphology and microstructure and Raman spectra are concerned. Although the major scientific goal of this study was to demonstrate and to investigate the variability of the presented methodology we also demonstrated some preliminary results about the reproducibility and the robustness of the method as well as the complete microchemical characterization of the generated carbonaceous particulate matter as well. However, it is noteworthy, that in order to introduce this methodology as a real alternative surrogate for modeling the real atmospheric soot aerosol further technical development is needed including, i.e., more robust and simplified excitation sources, more sophisticated physical and chemical characterization of the generated aerosol plume including measurement of, i.e., optical and thermochemical refractiveness parameters and detailed intercomparison study with the alternatives. These works are in progress and the related results are planned to be demonstrated in other studies.

\section{Summary}

In this work we generated carbonaceous particles by laser ablation of a high purity graphite disc. The complete microphysical parameters of the generated particles including number concentration, size distribution, morphology, microstructure, and molecule structure were characterized as a function of the generation parameters such as laser fluence, composition and the volumetric flow rate of the purging gas in the reaction chamber. This characterization proved a unique advantage of the proposed method, i.e., that the microphysical features of the generated particles can be controlled accurately and independently from one another. The proposed generator can produce particles either with spherical (primary particles) or with complex morphology (cluster aggregates), as well as a controlled mixture of these modes (Figs. 3 and 4) in an extremely wide size range covering the entire climate and health relevant domain. The measured microphysical properties confirm that the generated particles have properties which are very close to those of real atmospheric carbonaceous particulate (Figs. 7 and 8). A special advantage of the proposed method is its flexibility in the use of various gases and gas mixtures as local gas ambience during the formation of carbon particles. This opens up the possibility of quantitative investigation of the gas to aerosol interaction during the particle formations (Fig. 6). As a target material, not only graphite but coal samples can be used, for example, as was already demonstrated before (Ajtai et al., 2010). This gives further flexibility for the generation method.

Acknowledgements. Financial support by the Hungarian Scientific Research Foundation (OTKA, project no. K101905) is gratefully acknowledged. The European Union and the European Social Fund have provided financial support to the project under the project no. TÁMOP-4.2.2.A-11/1/KONV-2012-0047 and TÁMOP 
4.2.2.A-11/1/KONV-2012-0060. The authors would also like to express their gratitude for the financial support of the project GOP-1.1.1-11-2012-0114.

Edited by: P. Herckes

\section{References}

Ajtai, T., Filep, Á., Kecskeméti, G., Hopp, B., Bozóki, Z., and Szabó, G.: Wavelength dependent mass-specific optical absorption coefficients of laser generated coal aerosols determined from multi-wavelength photoacoustic measurements, Appl. Phys. A, 103, 1165-1172, 2010.

Allen, G., Sioutas, C., Koutrakis, P., Reiss, R., Lurmann, F. W., and Roberts, P. T.: Evaluation of the TEOM method for measurement of ambient particle mass in urban areas, J. Air Waste Ma., 47, 682-689, 1997.

Baumgardner, D., Popovicheva, O., Allan, J., Bernardoni, V., Cao, J., Cavalli, F., Cozic, J., Diapouli, E., Eleftheriadis, K., Genberg, P. J., Gonzalez, C., Gysel, M., John, A., Kirchstetter, T. W., Kuhlbusch, T. A. J., Laborde, M., Lack, D., Müller, T., Niessner, R., Petzold, A., Piazzalunga, A., Putaud, J. P., Schwarz, J., Sheridan, P., Subramanian, R., Swietlicki, E., Valli, G., Vecchi, R., and Viana, M.: Soot reference materials for instrument calibration and intercomparisons: a workshop summary with recommendations, Atmos. Meas. Tech., 5, 1869-1887, doi:10.5194/amt-51869-2012, 2012.

Bond, T. C., Doherty, S. J., Fahey, D. W., Forster, P. M., Berntsen, T., DeAngelo, B. J., Flanner, M. G., Ghan, S., Kärcher, B., Koch, D., Kinne, S., Kondo, Y., Quinn, P. K., Sarofim, M. C., Schultz, M. G., Schulz, M., Venkataraman, C., Zhang, H., Zhang, S., Bellouin, N., Guttikunda, S. K., Hopke, P. K., Jacobson, M. Z., Kaiser, J. W., Klimont, Z., Lohmann, U, Schwarz, J. P., Shindell, D., Storelvmo, T., Warren, S. G., and Zender, C. S.: Bounding the role of black carbon in the climate system: A scientific assessment, J. Geophys. Res.-Atmos., 118, 1-173, 2013.

Furhstorfer, P. and Niessner, R.: Identification and Classification of Airborne Soot Particles Using an Automated SEM/EDX, Mikrochim. Acta, 1134, 239-250, 1994.

Gelencsér, A.: Carbonaceous Aerosol, Springer-Verlag GmbH, ISBN 10: 1402028865/ISBN 13: 9781402028861, 2004.

Gysel, M., Laborde, M., Olfert, J. S., Subramanian, R., and Gröhn, A. J.: Effective density of Aquadag and fullerene soot black carbon reference materials used for SP2 calibration, Atmos. Meas. Tech., 4, 2851-2858, doi:10.5194/amt-4-2851-2011, 2011.

Hand, J. L., Malm, W. C., Laskin, A., Day, D., Lee, T., Wang, C., Carrico, C., Carrillo, J., Cowin, J. P., Collett, J., and Iedema, M. J.: Optical, physical, and chemical properties of tar balls observed during the Yosemite Aerosol Characterization Study, J. Geophys. Res., 110, D21210, doi:10.1029/2004JD005728, 2005.

Hawa, T. and Zachariah, M.: Coalescence kinetics of unequal sized nanoparticles, J. Aerosol Sci., 37, 1-15, 2006.

Hopp, B., Kecskeméti, G., Smausz, T., Ajtai, T., Filep, A., Utry, N., Kohut, A., Bozóki, Z., and Szabó, G.: Characterization of excimer laser ablation generated pepsin particles using multiwavelength photoacoustic instrument, Appl. Phys. A, 107, 429435, 2012.
Horvath, H. and Gangl, M.: A low-voltage spark generator for production of carbon particles, J. Aerosol. Sci., 34, 1581-1588, 2003.

IPCC: Intergovernmental Panel on Climate Change, Climate Change 2007: The Physical Science Basis - Summary for Policymakers, available at: http://www.ipcc.ch/pdf/assessment-report/ ar4/wg1/ar4_wg1_full_report.pdf (last access: 10 March 2015), Cambridge University Press, Cambridge, United Kingdom and New York, NY, USA, 2007.

Jawhari, T., Roid, A., and Casado, J.: Raman spectroscopic characterization of some commercially available carbon black materials, Carbom, 33, 1561-1565, 1995.

Kirchstetter, T. W. and Novakov, T.: Controlled generation of black carbon particles from acombustion flame and applications in evaluating black carbon measurement methods, Atmos. Environ., 41, 1874-1888, doi:10.1016/j.atmosenv.2006.10.067, 2007.

Kirchstetter, T. W., Novakov, T., and Hobbs, P. V.: Evidence that spectral light absorption by aerosols emitted from biomass burning and motor vehicles is different due to organic carbon, J. Geophys. Res., 109, D21208, doi:10.1029/2004JD004999, 2004.

Mertes, S., Dippel, B., and Schwarzenböck, A.: Quantifitaion of graphitic carbon in athmospheric aerosol particles by Raman soectroscopy and first application for the determination of mass absorption efficiencies, Aerosol Sci., 35, 347-361, 2004.

Park, K., Kittleson, D. B., and McMurry, P. H.: Structural Properties of Diesel Exhaust Particles Measured by Transmission Electron Microscopy (TEM): Relationships to Particle Mass and Mobility, Aerosol Sci. Tech., 38, 881-889, 2004.

Pope III, C. A. and Dockery, D. W.: Epidemiology of particulate effects, Air Poll. Health, 31, 673-705, 1999.

Randall, L. and Vander, W.: A TEM Methodology for the Study of Soot Particle Structure, Combustion Sci. Tech., 126, 333-351, 2010.

Ritikos, R., Rahman, S. A., Gani, S. M. Ab., Muhamad, M. R., and Yap, Y. K.: Catalyst-free formation of vertically-aligned carbon nanorods as induced by nitrogen incorporation, Carbon, 49, 1842-1848, 2011.

Sadecky, A., Muckenhuber, H., Grothe, H., Niessner, R., and Pöschl, U.: Raman microspectroscopy of soot realted carbonaceous materials: Spectral analysis and structural information, Carbon, 43, 1731-1742, 2005.

Schnaiter, M., Horvath, M., Möhler, O., Naumann, K. H., Saathol, H., and Schöck, O. W.: UV-VIS-NIR spectral optical properties of soot and soot-containing aerosols, Aerosol Sci., 34, 14211444, 2003.

Schnaiter, M., Gimmler, M., Llamas, I., Linke, C., Jäger, C., and Mutschke, H.: Strong spectral dependence of light absorption by organic carbon particles formed by propane combustion, Atmos. Chem. Phys., 6, 2981-2990, doi:10.5194/acp-6-2981-2006, 2006.

Song, J., Alam, M., and Boehman, A. L.: Characterization of diesel and biodiesel soot, Prepr. Pap.-AM. Chem. Soc., DIv. Fuel Chem., 49, 769, 2004.

Spanner, G., Schröder, H., Petzold, A., and Niessner, R.: Geneartion of carbon aerosols by fragmentation of acetylene in a laserinduced plasme, J. Aerosol Sci., 25, 265-275, 1994.

Sze, S.-K., Siddique, N., Sloan, J. J., and Escribano, R.: Raman spectroscopy characterization of carbonaceous aerosols, Atmos. Environ., 35, 561-568, 2001. 
Tumolva, L., Park, J.-Y., Kim, J., Miller, A. L., Chow, J. C., Watson, J. G., and Park, K.: Morphological and Elemental Classification of Freshly Emitted Soot Particles and Atmospheric Ultrafine Particles using the TEM/EDS, Aerosol Sci. Tech., 44, 202-215, 2010.

Voevodin, A. A., Jones, J. G., Zabinski, J. S., and Hultman, L.: Plasma characterization during laser ablation of graphite in nitrogen for the growth of fullerene-like $\mathrm{CN}_{\mathrm{X}}$ films, J. Appl. Phys., 92, 724, doi:10.1063/1.1481972, 2002.
Yang, L., May, P. W., Yin, L., Smith, J. A., and Rosser, K. N.: Ultra fine carbon nitride nanocrystals synthesized by laser ablation in liquid solution, J. Nanopart. Res., 9, 1181-1185, 2007. 